\title{
RAISING THE STANDARD: DEVELOPING A BENCHMARK FOR GREEN INFRASTRUCTURE
}

\author{
DANIELLE SINNETT ${ }^{1}$, GEMMA JEROME ${ }^{1,2}$, NICK SMITH ${ }^{1}$, SARAH BURGESS $^{1}$ \& ROGER MORTLOCK ${ }^{2}$ \\ ${ }^{1}$ Centre for Sustainable Planning and Environments, University of the West of England, United Kingdom. \\ ${ }^{2}$ Gloucestershire Wildlife Trust, United Kingdom.
}

\begin{abstract}
Green infrastructure (GI) is globally recognised as an essential component of liveable and sustainable places. It is valued for its multifunctionality and the connectedness of the individual features to each other, the surrounding countryside and urban populations. It brings together many land uses (e.g. parks, gardens, cemeteries, allotments, nature reserves, surface water), urban design (e.g. street trees, landscaping) and functional features (e.g. sustainable urban drainage systems, green roofs) operating at differing spatial scales. It is widely acknowledged that GI is the primary mechanism for delivering ecosystem services in towns and cities, and there is a substantial body of research demonstrating the multiple benefits of GI to urban populations. Despite this evidence base, there is still considerable uncertainty about the best way to design, deliver and maintain GI. This paper presents an emerging benchmark that has been developed through a combination of literature review and engagement with key stakeholders. It provides a suite of standards that are flexible enough to be used across different spatial scales depending on the specific needs of the location, covering the form and function of GI including nature conservation, water management, health and well-being, environmental and design quality. It allows an assessment of GI policy, and the planning, design, delivery and long-term management of GI in new and existing places, ensuring that current good practice is adopted at all stages. The development of the benchmark to date is summarised along with the outcome of preliminary testing using the outline planning applications for two contrasting mixed-use developments. This found that the benchmark performed well, with standards set at a level to ensure that high-quality GI is rewarded but without requiring a level of GI provision and quality that would only be expected on truly exemplary developments. Plans for the future development and testing of the benchmark are provided.

Keywords: biodiversity, ecosystem services, green infrastructure, green spaces, sustainable urban drainage, urban planning
\end{abstract}

\section{INTRODUCTION}

Green infrastructure (GI) is recognised globally as an essential component of liveable and sustainable places. It is generally defined as encompassing most vegetated elements in the built environment, for example, trees, shrubs, wetlands and other planting. An essential characteristic of GI is its multi-functionality and the connection between its features, the surrounding countryside and urban populations. It brings together many land uses (e.g. parks, cemeteries, nature reserves, surface water), urban design features (e.g. street trees, landscaping) and functional features (e.g. sustainable urban drainage systems, green roofs) operating at the building, neighbourhood, city and landscape scale [1,2]. The appropriate form, type and extent of GI varies within and between places, based on the needs of the locale. There is seldom a 'one size fits all' approach.

Green infrastructure is widely acknowledged as the primary mechanism for delivering ecosystem services in towns and cities, and most urban areas in the developed world have a GI strategy in some form. To support this, there is a substantial body of research demonstrating the multiple benefits of GI to urban populations. For example, GI has been found to:

- Benefit human health and well-being by providing spaces for rest and relaxation, play, physical activity, social interaction and reflection [3-5]; 
- Act as an educational resource, by teaching urban populations about natural processes, conservation and biodiversity $[6,7]$;

- Contribute to good place making, when integrated within the overall urban design, enhancing the quality of the built environment and, through this, quality of life $[4,8]$;

- Improve environmental quality through capturing harmful pollutants $[9,10]$; and

- Contribute to climate change adaptation by reducing surface and air temperatures [10, 11] and flood risk [12].

Related to these, GI has demonstrable economic benefits. These include those operating at a societal level, for example, through improvements to health and well-being and reduced risks to property and infrastructure (e.g. from flooding); and to the local economy through increased inward investment [13], increased tourism and visitors [14] and property prices [15-17].

Despite this evidence base, there is still considerable uncertainty as to how GI can best be delivered and maintained in practice. Whilst the multi-faceted nature and multi-functionality of GI is a strength, it can also be perceived as complex to those responsible for its delivery and management (e.g. [18]). This can waste resources as the different actors are unsure of what is expected of them, for example, to secure planning permission [19]. This has led to a plethora of information and guidance from numerous sources (e.g. [2], [19-22]). However, this guidance tends to be piecemeal, either dealing with only one stage of the GI process, or targeting one stakeholder group [23].

The suitability and quality of GI is critical. Green infrastructure will not be capable of delivering against its objectives if it is not fit for purpose or of insufficient quality. Without good practice, ill-conceived or poor-quality GI can adversely impact on, for example, open space use [24, 25], properties [26], biodiversity objectives and ecosystem service provision [27]. It is important that the most appropriate, high-quality GI is considered at all stages of the GI lifecycle. For example, policies that fail to match the objectives for GI with the likely outcomes from different features of GI may not deliver. Similarly, inappropriate planning and design of GI will not meet policy objectives or deliver beneficial outcomes, and GI that is not properly managed will not sustain positive outcomes over time.

The evidence base for GI demonstrates that successful delivery is a multi-disciplinary and multi-sector endeavour. It requires the effective collaboration of a range of built environment professionals (e.g. architects, planners, developers, urban designers, landscape architects, civil engineers) and other disciplines including ecologists, environmental scientists, arboriculturalists and public health experts. It also requires the effective involvement of private and public sectors, NGOs, communities, central and local government, professional bodies and academia. It is therefore critical that a common understanding of the appropriate standard of GI is developed that allows different disciplines and sectors to understand the GI solutions available to them, their capabilities and how they can be effectively delivered in the long term. These actors all have their own understanding of GI with few having the necessary broad-ranging expertise to ensure success.

Currently, there is no overarching benchmark or standard for GI [28]. In a review of 21 benchmarks, awards and systems used in the built environment, nine were specifically related to GI and the remainder were more general sustainability assessments, such as BREEAM Communities. Of those specific to GI, most were limited in their scope, for example, the Green Flag Award which is concerned with the quality of parks and greenspaces. The general sustainability assessments often contained some aspects of GI quality, but these are often limited [28, 29], for example only considering green spaces, or only focussed on the design with no evaluation of delivery or maintenance. However, what is lacking is a benchmark that 
provides a full assessment of GI, including its design, features, connectivity and long-term management. This is particularly important as often the provision of GI set out during the planning stages of a development is not delivered during construction. Similarly, the ability of GI to meet its objectives is strongly dependent on the extent to which it is maintained in the long term so any assessment process should consider whether adequate provision has been made for this.

The paper details the initial development and testing of a benchmark for GI in Gloucestershire and the West of England.

\section{BENCHMARK DEVELOPMENT}

The benchmark is being developed in collaboration between Gloucestershire Wildlife Trust and University of the West England, Bristol. The need for a benchmark was borne out of discussions with local stakeholders including property developers, planners, landscape architects, public health professionals and ecologists. The requirement for GI as part of new development in Gloucestershire is particularly comprehensive so the development sector knows that they must provide high-quality features to secure planning permission. However, they expressed frustration that the multi-faceted nature of GI and the vast array of 'good practice' that exists is causing uncertainty amongst the sector. This engagement with stakeholders established that the certainty provided by a benchmark would be beneficial to the successful delivery of GI in terms of both policy development and the industry response.

The stakeholder engagement, together with a review of national and local planning policy, identified a number of broad themes that the benchmark should cover. These included aspects seen as being key to successful GI (see below) and three thematic areas framed around the services that GI provides for nature conservation, water management, and health and wellbeing. It was also a requirement that the benchmark should be flexible enough for use across different spatial scales and stages in the development process (e.g. at outline planning through to post-construction), including for policies. It was stressed that it was important to set the standards at the 'right' level so that they are not so low that the benchmark would be awarded to all developments (i.e. only meeting statutory requirements) but not so high that it would act as a deterrent only relevant to truly exemplary schemes. To achieve this having different levels of award was seen as appropriate which is common across other built environment assessments methods. The overall aim of the benchmark was therefore seen as clarifying the expectations for GI and gently raising the standard of GI over time.

Taking these requirements into account, a review of existing criteria (for example, from accreditation tools and assessment methodologies), good practice guidance and other industry standards was conducted. This allowed a long list of potential standards to be compiled. A workshop was then held with the research team and some external advisors to consolidate the long list into a suite of draft standards. The outcome of this workshop was:

- Six mandatory standards covering key aspects of GI, including the creation of a multifunctional network, consideration of local priorities, contribution to environmental quality, and provision for long-term management arrangement;

- Six standards related to water management, including the need to minimise surface run-off and improve water quality;

- Six standards related to nature conservation, including providing ecological enhancement and considering nature conservation at all stages of development;

- Six standards related to health and well-being, including ensuring accessible, high-quality spaces for all and contributing to sense of place. 
Each of the thematic areas was divided into two levels with three standards each. First, 'achieve' standards seen as reflecting the minimum requirement for high-quality GI across these areas. Second, 'excellent' standards that would only be expected for truly exemplary examples of GI to give flexibility for applicants to demonstrate where a higher standard had been reached.

\section{PRELIMINARY TESTING}

Once a draft set of standards had been developed, these were tested on two contrasting developments (A and B) in Gloucestershire. The purpose of this was to test the standards against the requirements of the stakeholders and the aim of the benchmark. The developments were deliberately chosen based on a preliminary review and local knowledge to represent contrasting consideration of GI. This was to ensure that the standards are set at the right level whereby not all developments would be awarded the benchmark but that high-quality developments would meet the achieve standards with reasonable ease. Both are strategic, residential-led, mixed-use green field developments of around 1000-2500 dwellings with a range of community facilities and commercial premises.

A range of documents submitted as part of the application for outline planning permission were reviewed against the draft standards. It was decided that this was a sensible stage at which to assess the performance of the standards as it is likely that potential applicants would decide to work towards the benchmark at pre-application stage and so the standards need to reflect the type of information provided at this stage. Although a post-construction sign off would need to demonstrate that the standards had been maintained as the development progressed through the planning system, it was felt that waiting solely until post construction may be too late as many aspects of the planning and design of GI are in place and difficult to adjust retrospectively.

Following the assessment of the developments against the draft standards, different scoring options were also tested to ascertain the most appropriate method to achieve the desired simplicity and flexibility (Table 1) for the overall benchmark.

The outcome of this assessment was reviewed at a second workshop which sought to answer the following questions:

Table 1: Options for scoring the standards into an overall award for the benchmark.

\begin{tabular}{|c|c|c|c|c|}
\hline \multirow[b]{2}{*}{ Option } & \multicolumn{4}{|c|}{ Level of attainment } \\
\hline & 1 & 2 & 3 & 4 \\
\hline $\begin{array}{l}\text { 1: Strict two } \\
\text { levels }\end{array}$ & $\begin{array}{l}6 \text { mandatory }+9 \\
\text { achieve }\end{array}$ & $\begin{array}{l}6 \text { mandatory }+ \\
9 \text { achieve }+6 \\
\text { excellent }\end{array}$ & & \\
\hline $\begin{array}{l}\text { 2: Flexible two } \\
\text { levels }\end{array}$ & $\begin{array}{l}6 \text { mandatory }+6 \\
\text { achieve }\end{array}$ & $\begin{array}{l}6 \text { mandatory }+ \\
9 \text { achieve }+3 \\
\text { excellent }\end{array}$ & & \\
\hline 3: Four levels & $\begin{array}{l}6 \text { mandatory }+6 \\
\text { achieve }\end{array}$ & $\begin{array}{l}6 \text { mandatory }+9 \\
\text { achieve }\end{array}$ & $\begin{array}{l}6 \text { mandatory }+ \\
9 \text { achieve }+3 \\
\text { excellent }\end{array}$ & $\begin{array}{l}6 \text { mandatory }+ \\
9 \text { achieve }+6 \\
\text { excellent }\end{array}$ \\
\hline 4: Points-based & $\begin{array}{l}6 \text { mandatory }+9 \\
\text { points }\end{array}$ & \multicolumn{3}{|c|}{$\begin{array}{l}6 \text { mandatory }+15 \text { where achieve standards }=1 \text { point } \\
\text { points }\end{array}$} \\
\hline
\end{tabular}


- Are the mandatory standards the right level?

- Are we expecting too much/too little from development schemes/policies?

- Is poor/good GI appropriately reflected in the overall score of the benchmark?

- Are you surprised by the results of the desk study? (i.e. if you have reviewed the documentation, or if you are familiar with the schemes)

- Are there any unintended consequences of using one scoring option over another?

- Is there parity between the same levels across different themes?

\section{RESULTS}

This section considers the performance against the draft standards of each development in turn, followed by a discussion of the performance of standards and the options for scoring the standards into the overall award benchmark.

\subsection{Performance of development A}

The documents considered in the assessment of development A were the GI Parameter Plan, Sustainability Strategy, Heritage and Archaeology Assessment, Environmental Statement and consultation response from an urban designer and two ecologists. In addition, reference was made to the local planning policy to ascertain to what extent local policies and priorities had been considered in the proposed GI.

Overall development A performed poorly against the draft standards and as a result would not be awarded the benchmark based on the application for outline planning permission. The primary reasons for this are that the individual features of GI do not form a multifunctional network and there is very little information provided on the specific features of GI that will be included in the development and how they relate to the needs and priorities of the area.

Development A did not meet the requirements of the mandatory standards so additional consideration of the thematic standards would not have been necessary if this were a real application. For example, the features consisted of a series of isolated open spaces that were seldom connected, and when connectivity was provided these corridors were too small to provide any useful function in terms of nature conservation, water management or active travel. Similarly, there was no obvious connectivity through the development or to build features or the surrounding landscape, including to protected habitats adjacent to the proposed development. There was no consideration of the long-term management of the GI, including a protected habitat.

The only positive aspect in terms of the mandatory standards was that there was some consideration of community and stakeholder engagement. However, this was only in reference to improving access to nature through a nature reserve and an adjacent protected habitat, which would be likely to be detrimental to its quality despite the provision of a $30 \mathrm{~m}$ buffer. Overall, the proposal did not meet the standards required for nature conservation. Although there was appropriate surveying of existing habitats, the focus was on maintaining the existing condition of these as opposed to any meaningful ecological enhancement.

The proposal was in general unimaginative in terms of the function of GI, with no appreciation of the role GI can play in climate change adaptation, water management, improving environmental quality, ecological enhancement, health and well-being or sense of place. Where these aspects were considered the documents simply contained a reiteration of national and local policies with no articulation of how the GI would respond to these. For example, in the case of water management, a series of potential measures (e.g. SuDS, using best practice) were included 
with no firm commitment or integration into the overall design of the GI. Similarly, health and well-being was only considered through vague statements that a high-quality environment would be provided which meets the needs of residents but there was no detail as to precisely if and how GI would contribute to this. There was some detail on the provision of play equipment and areas for natural play but no indication of the accessibility of these features to new or existing residents. Throughout there was no consideration of the multifunctionality of the GI, for example how water management spaces could impact on biodiversity or their role in providing visual amenity or spaces for recreation.

Overall, development A was felt to be a poor example that does not regard the development as an opportunity to enhance GI for the benefit of existing residents, incoming residents and the wider landscape.

\subsection{Performance of development B}

The documents considered in the assessment of development B were the GI Assets, GI Parameter Plan, GI Strategy, Environmental Statement, and Environmental Impact Assessment. Reference was also made to local planning policy.

The provision for GI in development B was judged to be of sufficient quality to meet the mandatory and 'achieve' standards across all three thematic areas and some of the 'excellent' standards. This development would be awarded the benchmark based on the documents reviewed.

It was clear from the documentation that the GI forms a coherent multifunctional network. A detailed description of baseline GI illustrating the local landscape, ecological and heritage designations, wider ecological networks, landscape character, flood plain and surface waters. The relationship between the relevant policies and the rationale for the GI approach, and how the proposed GI would contribute to these was articulated. The role of GI in climate change adaptation, including in mitigating the impact of development on the natural environment in terms of maintaining ecological networks, air, soil and water quality and providing water management was also considered. Development B was particularly comprehensive in its consideration of the long-term maintenance and management of the GI, an aspect that would not usually be included at this stage in the planning process. This recognised the importance of management in ensuring GI function and the need for a GI Management Scheme to be provided as a planning condition. This would explore options for funding (e.g. developer contributions, management charges, endowment and revenue generation) and governance (e.g. private management, public sector, voluntary organisations and community trusts). Related to this, there was appreciation of the importance of community participation in the decision-making process, on site activities and long-term management, including ways to achieve this.

Although it was clear that the GI would form a coherent ecological network on the development site, it was not clear how it would contribute to the wider ecological networks surrounding the development. Throughout the proposal, there is a great level of detail provided. For example, an appropriate range of habitat types is considered (e.g. trees, woodlands, hedgerows, grassland) as well as how these will be protected and enhanced through all stages of construction process. Similarly, a SuDS strategy is provided which includes an assessment of the sensitivity of receiving waters and floodplain to development with the SuDS ensuring that there is negligible effect on water quality and levels. This also details the disposal of surface water run-off, the specific SuDS features that will be included along with 
their performance in terms of water attenuation and quality, with clear reference to CIRIA's SuDS Manual [30] and local guidance. There are also clear links between the local strategies for sport and recreation and the comprehensive range of open spaces provided with a representation of the proximity of open spaces to dwellings to demonstrate their accessibility.

Throughout the proposal documents, there is reference to the multifuctionality of the GI. This includes, for example, the role of allotments, orchards, play and recreational areas, and active travel routes in enhancing biodiversity, and the integration of SuDS features with informal open space and GI corridors and their contribution to recreation, visual amenity, biodiversity and the character of the development.

Development B is a good example of GI, which is supported by the scoring shown below. The scheme would be considered for the award as it meets the mandatory and 'achieve' standards.

\subsection{Performance of the standards}

Overall, the standards performed well in assessing the two developments. They appear to be set at an appropriate level so that the development considered to have poorly considered GI would not be awarded the benchmark, whereas the development with well thought out GI with a high level of detail would. It was reassuring that the standards were set at the level that a high-quality development that had not knowingly applied for the benchmark performed well as this suggests that the requirements are realistic and expectations are not too high in terms of the GI provision. In terms of the evidence needed to demonstrate that the standards had been met the documentation provided by development B was generally sufficient to ascertain that the mandatory and 'achieve' standards had been met. This suggests that the application process for the benchmark would not be too onerous and that it should simply require a consolidation of existing evidence to respond to each standard; this should reduce the costs of certification as all the evidence would be in one place instead of spread across multiple documents.

However, it was relatively difficult to judge whether the 'excellent' standards had been met based on the documentation reviewed. For example, the role of the GI in wider ecological networks, provision for building-scale GI, the contribution to reducing health inequalities and how barriers to GI access for vulnerable groups would be overcome were all missing from the documentation. First, this is not a fair assessment as these developments did not set out to apply for the benchmark so did not know to provide this information. Second, much of this detail would not usually be provided for outline planning permission and would come later in the planning process, either in the full planning application on in reserved matters. It is unlikely that developers will be willing to provide additional information for a non-statutory requirement so it is likely that no differentiation would be made in the initial pre-construction assessment between 'achieve' and 'excellent' awards, but those aiming for 'excellent' would be working towards this throughout the development process.

\subsection{Options for scoring for the overall benchmark}

The second workshop also considered the different options for scoring set out in Table 1 . Development A did not meet the full set of mandatory standards and would therefore be ineligible for accreditation irrespective to the scoring mechanism. However, development B does meet 
Table 2: Options for scoring the standards for development B.

\begin{tabular}{|c|c|c|c|}
\hline Option & Level 1 & Level 2 & Comments \\
\hline $\begin{array}{l}\text { 1: Strict two } \\
\text { levels }\end{array}$ & $\begin{array}{l}6 \text { mandatory }+9 \\
\text { achieve }\end{array}$ & & $\begin{array}{l}\text { Simpler to administer and under- } \\
\text { stand, but little flexibility }\end{array}$ \\
\hline $\begin{array}{l}\text { 2: Flexible two } \\
\text { levels }\end{array}$ & $\begin{array}{l}6 \text { mandatory }+6 \\
\text { achieve }\end{array}$ & & $\begin{array}{l}\text { More flexible, but little incentive to } \\
\text { meet all 'achieve' standards }\end{array}$ \\
\hline 3: Four levels & & $\begin{array}{l}6 \text { mandatory }+9 \\
\text { achieve }\end{array}$ & $\begin{array}{l}\text { Flexible across levels and themes, } \\
\text { but more complex }\end{array}$ \\
\hline 4: Points-based & $\begin{array}{l}6 \text { mandatory }+11 \\
\text { points }\end{array}$ & & $\begin{array}{l}\text { Most flexible, also most complex, } \\
\text { can be 'excellent' with less }\end{array}$ \\
\hline
\end{tabular}

these standards as well as a number of the 'achieve' and 'excellent' standards and its scores are shown in Table 2. There was very little difference between the scoring systems with development B meeting the requirements of level 1 in options 1, 2 and 4 and level 2 in option 3 out of a 4 possible levels. The initial suggestion is therefore to proceed with option 1 and call the two levels 'achieve' and 'excellent' as this is the simplest option, which will be most easily understood by applicants.

\subsection{Limitations}

There are a number of limitations to this preliminary testing. First, as alluded to above the developments did not set out to apply for the benchmark when formulating the documents used to assess their consideration of GI so the judgements provided here should be taken with this in mind. However, given that the benchmark is not a statutory requirement this is a good test of whether the benchmark is asking for additional information than would normally be required in a planning application. In the case of development $\mathrm{A}$, the comments from the statutory consultees suggest that this development falls short of what would be required in terms of the GI for planning permission to be granted.

Second, both of the developments considered are strategic developments where there is, arguably, more scope for the creation of a multifunctional network of GI. The benchmark would need to be assessed on smaller developments or urban infill to ensure that it is also fit for purpose in these scenarios. The standards emphasis that the GI should be appropriate for the site in question so this should mean that it is flexible enough to be used on these types of development, and testing will ascertain whether this is the case. Its performance in assessing the standard of GI policy documents also needs to be ascertained.

Finally, the benchmark would need to be tested at the different stages of the development process. Here, it is has only been tested on two development applications for outline planning permission. However, often the provision for GI is diminished as the plans develop and upon construction. One of the major concerns of stakeholders was that there should be a postconstruction check before the full benchmark is awarded to overcome this and so this will need to be tested in practice. It is suggested that this is complementary to the issues discussed above regarding the assessment of the 'excellent' standards in an application for outline planning permission. So, that a scheme is awarded 'candidate' status on the basis of meeting the six mandatory and nine 'achieve' standards during the planning process, with the full differentiation between 'achieve' and 'excellent' not being made until after construction. 


\section{FUTURE DEVELOPMENTS}

To overcome some of the limitations discussed above, the standards are currently being tested in a suite of 'front runner' new developments, including strategic urban extensions on greenfield sites and small infill brownfield developments, and policy documents. There is ongoing refinement of the standards through this testing and consultations with local stakeholders and an external advisory group.

This work is also testing the process for awarding the benchmark. It is envisaged that a trained assessor, embedded in the applicant team (e.g. a landscape architect) will work towards the benchmark and provide the supporting evidence with the application to an external certification body who will be responsible for the final assessment and awarding of the benchmark. Following this testing period, the standards and technical guidance document will be freely available.

\section{CONCLUSIONS}

Green infrastructure is an essential component of high-quality, sustainable and healthy places. Despite an abundance of guidance there is still a lack of certainty on how GI can best be delivered and maintained in practice. Extensive engagement with stakeholders has suggested that there is a need for a benchmark to provide this certainty to both planners and developers, and the form that such a benchmark should take. The benchmark has been developed in accordance with good practice for GI planning, design, delivery and maintenance, based on its beneficial role in nature conservation, water management, and health and well-being. The preliminary testing of the benchmark suggested that the 24 standards performed well in terms of ensuring that only high quality provision of GI would be rewarded, yet realistic in terms of what developers would be prepared to deliver. Further testing is underway on live projects including new developments and policy documents. So far, the response in the preliminary testing and from stakeholders suggests that the benchmark will provide clarity to the sector and ultimately achieve its aim of raising the standard of GI.

\section{ACKNOWLEDGMENTS}

We thank Tom Calvert (UWE), Colin Studholme (GWT) and Steve Bloomfield (Worcestershire Wildlife Trust) for their contribution to the development of the standards along with the comments and support from the local stakeholders, front runner projects and external advisory group. This work is funded by Innovate UK and NERC through a Knowledge Transfer Partnership between UWE and GWT (Grant number: 1011832).

\section{REFERENCES}

[1] Burgess, S. Multifunctional green infrastructure: a typology. Handbook on Green Infrastructure, ed. D. Sinnett, N. Smith, S. Burgess, Edward Elgar: Cheltenham, pp. 227-241, 2015.

[2] RICS. Green infrastructure in urban areas. Information Paper. RICS: London, 2011.

[3] Tzoulas, K., Korpela, K., Venn, S., Yli-Pelonen, V., Kaźmierczak, A., Niemela, J. \& James, P., Promoting ecosystem and human health in urban areas using green infrastructure: A literature review. Landscape \& Urban Planning, 81, pp. 167-178, 2007. https://doi.org/10.1016/j.landurbplan.2007.02.001

[4] Ward Thompson, C., Activity, exercise and the planning and design of outdoor spaces. Journal of Environmental Psychology, 34, pp. 79-96, 2013. https://doi.org/10.1016/j.jenvp.2013.01.003 
[5] Hunter, R., Christian, H., Veitch, J., Astell-Burt, T., Hipp, J., \& Schipperijn, J., The impact of interventions to promote physical activity in urban green space: a systematic review and recommendations for future research. Social Science \& Medicine, 124, pp. 246-256, 2015. https://doi.org/10.1016/j.socscimed.2014.11.051

[6] Miller, J.R., Biodiversity conservation and the extinction of experience. Trends in Ecology and Evolution, 20, pp. 430-434, 2005. https://doi.org/10.1016/j.tree.2005.05.013

[7] CABE, Urban Green Nation: Building the evidence base. CABE Space: London, 2010.

[8] Peters, K., Elands, B., \& Buijs, A., Social interactions in urban parks: stimulating social cohesion? Urban Forestry and Urban Greening, 9, pp. 93-100, 2010. https://doi.org/10.1016/j.ufug.2009.11.003

[9] Tallis, M., Freer-Smith, P., Sinnett, D., \& Taylor, G., Estimating the removal of atmospheric particulate pollution by the urban tree canopy of London, under current and future environments. Landscape \& Urban Planning, 103, pp. 129-138, 2011. https://doi.org/10.1016/j.landurbplan.2011.07.003

[10] Demuzere, M., Orru, K. Heidrich, O., Olazabal, E., Geneletti, D., Orru, H., Bhave, A.G., Mittal, N. \& Faehnle, M., Mitigating and adapting to climate change: Multi-functional and multi-scale assessment of green urban infrastructure. Journal of Environmental Management, 146, pp. 107-115, 2014. https://doi.org/10.1016/j.jenvman.2014.07.025

[11] Doick, K.J. \& Hutchings, T.R., Air temperature regulation by trees and wider green infrastructure in urban areas: the current state of knowledge. Research Note 12. Forestry Commission: Edinburgh, 2013.

[12] Lamond, J., Wilkinson, S., Rose, C., Proverbs, D., Sustainable urban drainage: Retrofitting for improved flood mitigation in city centres. RICS: London, 2014.

[13] Rolls, S. \& Sunderland, T., Microeconomic evidence for the benefits of investment in the environment 2 (MEBIE2). NERR057. Natural England: Swindon, 2014.

[14] Saraev, V., Economic benefits of greenspace. Forestry Commission: Edinburgh, 2012.

[15] Dunse, N., White, M. \& Dehring, C., Urban parks open space and residential property values. RICS Research Paper Series, September. RICS: London, 2007.

[16] McCord, J., McCord, M., McCluskey, W., Davis, P.T., McIlhatton, D. \& Haran, M., Effect of public green space on residential property values in Belfast metropolitan area. Journal of Financial Management of Property and Construction, 19, pp. 117-137, 2014.

[17] Mourato, S., Atkinson, G., Collins, M., Gibbons, S., MacKerron, G. \& Resende, G., Economic analysis of cultural services. The UK National Ecosystem Assessment, Technical Report. UNEP-WCMC: Cambridge, 2010.

[18] Matthews, T., Lo, A.Y. \& Bryne, J.A., Reconceptualizing green infrastructure for climate change adaptation: Barriers to adoption and drivers for uptake by spatial planners. Landscape \& Urban Planning, 138, 155-163, 2015. https://doi.org/10.1016/j.landurbplan.2015.02.010

[19] UK Green Building Council, Demystifying green infrastructure. UK Green Building Council, 2015.

[20] CIWEM, Multi-functional urban green infrastructure, A CIWEM Briefing Report. CIWEM: London, 2010. 
[21] TCPA and The Wildlife Trusts, Planning for a healthy environment: Good practice guidance for green infrastructure and biodiversity. TCPA and The Wildlife Trusts, 2012.

[22] Science for Environment Policy, The multifunctionality of green infrastructure. In-depth Report. DG Environment, European Commission: Brussels, 2012.

[23] Sinnett, D., Calvert, T., Martyn, N., Williams, K., Burgess, S., Smith, N. \& King, L., Green infrastructure: Research into practice. University of the West of England: Bristol, 2016. Available at: www.eprints.uwe.ac.uk/29515. (accessed 6 March 2017).

[24] Greenspace, The park life report. Greenspace: Reading, 2007.

[25] Coombes, E., Jones, A.P. \& Hillsdon, M., The relationship of physical activity and overweight to objectively measured green space accessibility and use. Social Science \& Medicine, 70, pp. 816-822, 2010.

https://doi.org/10.1016/j.socscimed.2009.11.020

[26] Roberts, J., Jackson, N. \& Smith, M., Tree roots in the built environment. Research for Amenity Trees No. 8. DCLG: London, 2006.

[27] Felson, A.J., Oldfield, E.E. \& Bradford, M.A., Involving ecologists in shaping largescale green infrastructure projects. Professional Biologist, 63, 882-890, 2013. https://doi.org/10.1525/bio.2013.63.11.7

[28] Smith, N., Calvert, T., Sinnett, D., Burgess, S. \& King, L., National benchmark for green infrastructure: A feasibility study. University of the West of England, Bristol, 2016. Available at: www.eprints.uwe.ac.uk/29514. (accessed 6 March 2017).

[29] Beauchamp, P. \& Adamowski, J. An integrated framework for the development of green infrastructure: A literature review. European Journal of Sustainable Development, 2, $1-24,2013$. https://doi.org/10.14207/ejsd.2013.v2n3p1

[30] Woods Ballard, B., Wilson, S., Udale-Clarke, H., Illman, S., Scott, T., Ashley, R. \& Kellagher, R., The SuDS Manual, C753. CIRIA: London, 2015. 